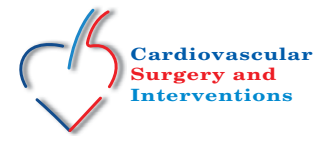

\title{
Hemoglobin A1c levels do not predict primary arteriovenous fistula failure in hemodialysis patients
}

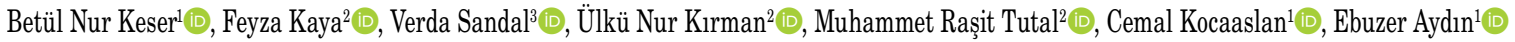 \\ ${ }^{1}$ Department of Cardiovascular Surgery, Faculty of Medicine, Istanbul Medeniyet University, Göztepe Prof. Dr. Süleyman Yalçın City Hospital, Istanbul, Turkey \\ ${ }^{2}$ Istanbul Medeniyet University, Göztepe Prof. Dr. Süleyman Yalçın City Hospital, Istanbul, Turkey \\ ${ }^{3}$ Faculty of Medicine, Istanbul Medeniyet University, Göztepe Prof. Dr. Süleyman Yalçın City Hospital, Istanbul, Turkey
}

Received: July 26, 2021 Accepted: October 18, 2021 Published online: November 12, 2021

\begin{abstract}
Objectives: In this study, we aimed to assess whether higher preoperative levels of glycated hemoglobin (HbA1c) could predict primary arteriovenous fistula (AVF) failure and to investigate the effect of diabetes mellitus on primary arteriovenous failure.

Patients and methods: Between July 2018 and August 2019, a total of 127 newly created AVFs in 117 patients (67 males, 50 females; mean age: $62.4 \pm 12.2$ years; range, 18 to 86 years) who underwent primary AVF operation in our cardiovascular surgery clinic were retrospectively analyzed. Medical data were obtained from the institutional database. Arteriovenous fistula failure was evaluated during follow-up.

Results: Primary AVF failure was seen in 24 (18.9\%) patients. Patients with diabetes mellitus had a higher ratio of failure compared to those without $(62.5 \%$ vs. $38.8 \%$, respectively; $\mathrm{p}=0.035)$. After adjustment, diabetes mellitus was not found to be an independent risk factor for AVF failure ( $p>0.05)$. There was no significant correlation between HbA1c levels and fistula failure ( $p>0.05)$.

Conclusion: Our study results suggest that diabetes is associated with AVF failure, but it is not an independent risk factor for AVF failure. Higher HbA1c levels fail to predict AVF failure.
\end{abstract}

Keywords: Arteriovenous fistula, blood glucose, diabetes mellitus, glycated hemoglobin.

Diabetes mellitus (DM) is the leading etiology in chronic kidney disease (CKD), and it is commonly accompanied byvascularcomplications. ${ }^{[1,2]}$ Other than changes in vascular homeostasis and accompanying medical conditions, prolonged hyperglycemia, itself, also plays a role in the pathophysiology of the vascular damage in these patients. ${ }^{[2]}$ Glycated hemoglobin (HbA1c) is the preferred blood marker of glycemic control in patients with DM and the current guideline of Kidney Disease Outcomes Quality Initiative (KDOQI) recommends a target $\mathrm{HbA} 1 \mathrm{c}$ of $<7 \%$ for DM patients, irrespective of the presence of CKD. ${ }^{[1]}$

Arteriovenous fistula (AVF) is the recommended vascular access type for hemodialysis according to the recent guideline of KDOQI. ${ }^{[3]}$ In addition to AVF having superior patency and lower re-intervention rates compared to other vascular access types, it has been found to be associated with lower rates of complication, infection, hospitalization, and depression and reduced costs and increased survival benefits. ${ }^{[4-7]}$ Nevertheless, fistula failure is still a challenge. Identifying the factors affecting primary AVF failure is crucial to improve the implementation of optimal hemodialysis therapy. Since DM is the most commonly accompanying disease on $\mathrm{CKD}$, assessment of the effect of DM-related parameters on AVF patency is of particular importance.

Considering that hyperglycemia is one of the reasons of vascular damage in patients with diabetes, we hypothesized that levels of $\mathrm{HbA1c}$ could affect AVF maturation. In the present study, we aimed to investigate whether higher preoperative levels of HbA1c could predict primary AVF failure and to

Corresponding author: Betül Nur Keser, MD. İstanbul Medeniyet Üniversitesi Göztepe Prof. Dr. Süleyman Yalçın Şehir Hastanesi Kalp ve Damar Cerrahisi Kliniği, 34722 Kadıköy, İstanbul, Türkiye.

Tel: +90 216 - 2803333 e-mail: keserbetulnur@gmail.com

\section{Citation:}

Keser BN, Kaya F, Sandal V, Kırman ÜN, Tutal MR, Kocaaslan C, et al. Hemoglobin A1c levels do not predict primary arteriovenous fistula failure in hemodialysis patients. Cardiovasc Surg Int 2021;8(3):139-144. 
examine the optimal cut-off value of $\mathrm{HbA1c}$ level to predict AVF failure.

\section{PATIENTS AND METHODS}

This single-center, retrospective study was conducted at Istanbul Medeniyet University Göztepe Prof. Dr. Süleyman Yalçın City Hospital, Department of Cardiovascular Surgery between July 2018 and August 2019. Initially, a total of 199 primary AVF operations were screened. Exclusion criteria were as follows: age $<18$ years $(n=8)$, undergoing arteriovenous graft operation and having incomplete data $(n=15)$. In addition, six patients who died before the study was completed and 43 patients who were lost-to-follow-up were excluded. Finally, a total of 127 newly created AVFs in 117 patients (67 males, 50 females; mean age: $62.4 \pm 12.2$ years; range, 18 to 86 years) were included in the study. A written informed consent was obtained from each patient. The study protocol was approved by the Istanbul Medeniyet University Göztepe Prof. Dr. Süleyman Yalçın City Hospital Ethics Committee (No. 0034-2019). The study was conducted in accordance with the principles of the Declaration of Helsinki.

\section{Data collection}

Data including demographic and clinical characteristics of the patients such as age, sex, height, weight and smoking habit; comorbidities (e.g., hypertension, DM, and peripheral artery disease); usage of antiplatelet or anticoagulant medications, history of undergoing hemodialysis through central venous catheter (CVC); and AVF failure were noted. Patients with DM or hypertension were identified as the ones who were under treatment with oral antidiabetic drugs or insulin, and antihypertensive drugs, respectively. Preoperative levels of red blood cells, HbA1c, blood glucose, white blood cells, platelet count, creatinine, and estimated glomerular filtration rate were documented. The tests were done up to two weeks prior to operations. All the values were measured by the hospital laboratory, and there was no considerable change in the measurement methods during the study.

Preoperative Doppler ultrasound mapping was routinely performed to each patient, and vascular diameters were noted. All operated patients had a vein diameter over $2.5 \mathrm{~mm}$ under tourniquet and an artery diameter over $2.0 \mathrm{~mm}$. All operations were performed by a single surgeon and, thus, the surgical approach to AVF creation was similar. The primary outcome of this study was primary AVF failure at six weeks. Primary AVF failure was defined as thrombosis or failure to mature at six weeks. ${ }^{[8]}$ Failure to mature was defined as insufficient flow to maintain dialysis or the inability to cannulate an $\mathrm{AVF}$, if required. ${ }^{[9]}$

\section{Statistical analysis}

Statistical analysis was performed using the IBM SPSS version 24.0 software (IBM Corp., Armonk, NY, USA). Descriptive data were expressed in mean \pm standard deviation (SD), median (min-max) or number and frequency, where applicable. The Kolmogorov-Smirnov test was applied to test normality. The Pearson chi-square, Mann-Whitney U, Kruskal-Wallis, and binary logistic regression tests were implemented, accordingly. Multiple logistic regression analyses were applied to evaluate independent risk factors for AVF failure. The variables included in the regression models were selected using the forward selection method. Multicollinearity diagnosis tests were performed for both multiple logistic regression models. The receiver operating characteristic (ROC) curve analysis was performed to identify the optimal cut-off value of $\mathrm{HbA1c}$ level to predict AVF failure. A $p$ value of $<0.05$ was considered statistically significant.

\section{RESULTS}

The rate of DM and hypertension was $43.3 \%$ $(\mathrm{n}=55)$ and $76.4 \%(\mathrm{n}=97)$, respectively. A total of $94(74.0 \%)$ of the operations were distal radiocephalic AVF operations, while there were 23 (18.1\%) proximal radiocephalic, four (3.1\%) brachiobasilic and six (4.7\%) brachiocephalic AVF operations. Primary failure was seen in 24 operations (18.9\%). Demographic and clinical characteristics of the patients with and without primary AVF failure are summarized in Table 1.

Diabetes mellitus was found to be associated with AVF failure. Patients with DM had a statistically significantly higher ratio of failure $(15 / 55 ; 27.3 \%)$, compared to those without DM $(9 / 72 ; 12.5 \%)$ $(p=0.035)$. Nevertheless, after adjustment, neither DM nor other parameters were found to be independent risk factors for AVF failure (Table 2). In addition, there was no significant correlation 


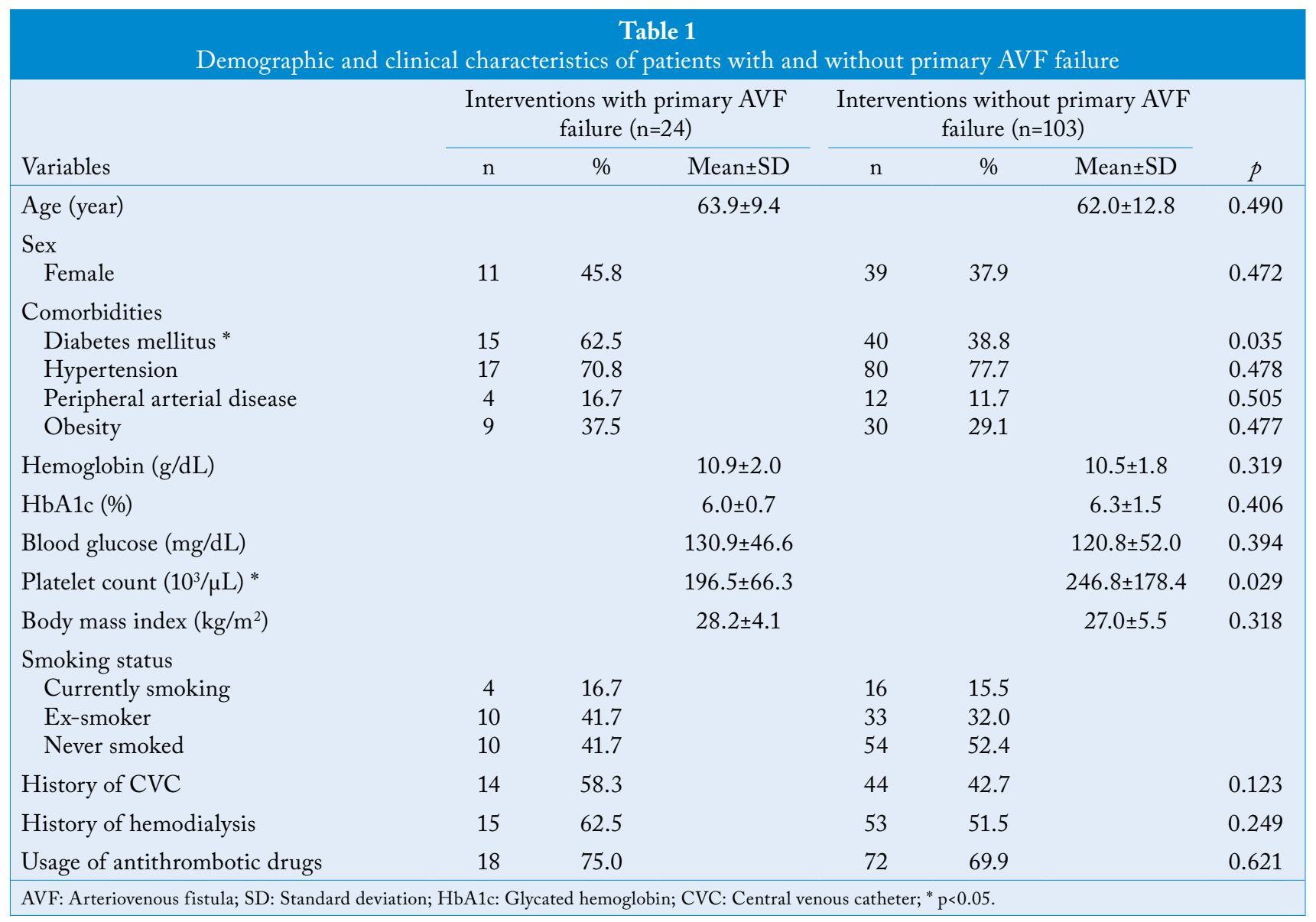

between HbA1c levels and primary AVF failure $(p=0.406)$. The ROC curve analysis established no cut-off value of $\mathrm{HbA} 1 \mathrm{c}$ level to predict primary AVF failure.

Patients with DM were older $(\mathrm{p}<0.001)$, had higher prevalence of hypertension $(\mathrm{p}=0.035)$, peripheral artery disease $(\mathrm{p}=0.001)$, and antithrombotic drug use $(\mathrm{p}=0.018)$, had higher levels of blood glucose $(\mathrm{p}<0.001)$ and HbA1c $(\mathrm{p}<0.001)$, higher body mass index values $(\mathrm{p}=0.014)$ and lower creatinine levels $(\mathrm{p}=0.020)$.

In subgroup analysis containing only patients with DM $(n=55)$, mean blood glucose level was

\begin{tabular}{|lccc|}
\multicolumn{4}{c}{ Table 2} \\
Multivariate logistic regression for primary arteriovenous fistula failure \\
\hline Covariates & Adjusted Odds Ratio & $95 \%$ CI & $p$ \\
\hline Age & 0.988 & $0.938-1.040$ & 0.640 \\
Diabetes mellitus & 2.455 & $0.488-12.347$ & 0.276 \\
HbA1c (\%) & 0.782 & $0.403-1.518$ & 0.467 \\
Blood glucose $(\mathrm{mg} / \mathrm{dL})$ & 0.999 & $0.987-1.012$ & 0.933 \\
Hypertension & 0.730 & $0.191-2.789$ & 0.645 \\
Peripheral artery disease & 0.926 & $0.144-5.963$ & 0.935 \\
Platelet count $\left(10^{3} / \mu \mathrm{L}\right)$ & 0.995 & $0.987-1.003$ & 0.245 \\
Antiplatelet usage & 1.025 & $0.327-3.212$ & 0.967 \\
\hline HbA1c: Glycated hemoglobin; CI: Confidence interval. & & \\
\hline
\end{tabular}




\begin{tabular}{|c|c|c|c|c|c|c|c|}
\hline \multirow[b]{3}{*}{ Variables } & \multicolumn{6}{|c|}{$\begin{array}{l}\text { Table } 3 \\
\text { ics of the patients with }\end{array}$} & \multirow[b]{3}{*}{$p$} \\
\hline & \multicolumn{3}{|c|}{$\begin{array}{l}\text { Interventions with primary AVF } \\
\text { failure }(\mathrm{n}=15)\end{array}$} & \multicolumn{3}{|c|}{$\begin{array}{l}\text { Interventions without primary AVF } \\
\text { failure }(\mathrm{n}=40)\end{array}$} & \\
\hline & $\mathrm{n}$ & $\%$ & Mean $\pm S D$ & $\mathrm{n}$ & $\%$ & Mean $\pm S D$ & \\
\hline Age (year) & & & $67.0 \pm 7.7$ & & & $67.8 \pm 10.4$ & 0.783 \\
\hline $\begin{array}{l}\text { Sex } \\
\text { Female }\end{array}$ & 7 & 46.7 & & 35 & 87.5 & & 0.912 \\
\hline $\begin{array}{l}\text { Comorbidities } \\
\text { Hypertension } \\
\text { Peripheral arterial disease } \\
\text { Obesity }\end{array}$ & $\begin{array}{c}12 \\
4 \\
6\end{array}$ & $\begin{array}{l}80.0 \\
26.7 \\
40.0\end{array}$ & & $\begin{array}{c}35 \\
9 \\
14\end{array}$ & $\begin{array}{l}87.5 \\
22.5 \\
35.0\end{array}$ & & $\begin{array}{l}0.482 \\
0.746 \\
0.731\end{array}$ \\
\hline Hemoglobin $(\mathrm{g} / \mathrm{dL})$ & & & $10.7 \pm 1.9$ & & & $10.5 \pm 1.8$ & 0.735 \\
\hline HbA1c (\%) & & & $6.2 \pm 0.7$ & & & $7.2 \pm 1.7$ & 0.054 \\
\hline Blood glucose (mg/dL) & & & $152.7 \pm 47.4$ & & & $158.1 \pm 60.8$ & 0.759 \\
\hline $\begin{array}{l}\text { Antidiabetic drug type } \\
\text { Insulin } \\
\text { Oral antidiabetic }\end{array}$ & $\begin{array}{c}11 \\
4\end{array}$ & $\begin{array}{l}73.3 \\
26.7\end{array}$ & & $\begin{array}{l}25 \\
15\end{array}$ & $\begin{array}{l}62.5 \\
37.5\end{array}$ & & 0.452 \\
\hline Platelet count $\left(10^{3} / \mu \mathrm{L}\right) *$ & & & $185.5 \pm 66.5$ & & & $242.9 \pm 72.4$ & 0.016 \\
\hline Body mass index $\left(\mathrm{kg} / \mathrm{m}^{2}\right)$ & & & $29.2 \pm 3.7$ & & & $28.4 \pm 5.3$ & 0.584 \\
\hline History of CVC & 10 & 66.7 & & 16 & 40.0 & & 0.051 \\
\hline History of hemodialysis & 11 & 73.3 & & 22 & 55.0 & & 0.142 \\
\hline Usage of antithrombotic drugs & 13 & 86.7 & & 32 & 80.0 & & 0.568 \\
\hline
\end{tabular}

\begin{tabular}{|c|c|c|c|}
\hline \multicolumn{4}{|c|}{$\begin{array}{l}\text { Table } 4 \\
\text { Multivariate logistic regression for primary arteriovenous fistula failure in patients } \\
\text { with diabetes mellitus }\end{array}$} \\
\hline Covariates & Adjusted Odds Ratio & $95 \% \mathrm{CI}$ & $p$ \\
\hline HbA1c (\%) & 0.543 & $0.237-1.244$ & 0.149 \\
\hline Platelet count $\left(10^{3} / \mu \mathrm{L}\right)$ & 0.993 & $0.980-1.006$ & 0.275 \\
\hline
\end{tabular}

$156.7 \pm 57.3 \mathrm{mg} / \mathrm{dL}$ and mean $\mathrm{HbA} 1 \mathrm{c}$ value was $7.0 \pm 1.6 \%$. Characteristics of the patients with $\mathrm{DM}$ are summarized in Table 3 . No significant correlation was detected between blood glucose levels and HbA1c levels in patients with DM $(p=0.433)$. The HbA1c level was not associated with AVF failure $(p=0.054)$. Lower levels of platelet count were observed in patients with AVF failure $(p=0.016)$. However, adjustment tests eliminated the statistical significance of the observations, and analysis revealed no independent risk factor for AVF failure in hemodialysis patients with DM (Table 4). No multicollinearity was detected in both regression models.

\section{DISCUSSION}

In the present study, the primary AVF failure was seen in $18.9 \%$ of the operations. Our study revealed that patients with DM had a statistically significantly higher ratio of primary AVF failure, but DM was not an independent risk factor for AVF failure. Higher levels of $\mathrm{HbA1c}$ failed to predict AVF failure.

A recent meta-analysis demonstrated a higher rate of AVF failure in patients with diabetes, ${ }^{[10]}$ which is consistent with our study. Other than hyperglycemia inducing vascular damage itself, metabolic changes accompanying DM such as endothelial damage and endothelial dysfunction impair venous remodeling 
and may result in failure to mature. ${ }^{[2,10]}$ Besides, $\mathrm{DM}$ is associated with an increased extracellular matrix deposition, deregulated growth factors, and pro-thrombotic activity and it is a known risk factor for atherosclerosis, which all may promote AVF failure. ${ }^{[11]}$

Our study demonstrated that preoperative levels of $\mathrm{HbA1c}$ failed to be a predictor of AVF failure. No consensus has been reached in the literature on whether HbA1c level has an impact on AVF failure. Some authors have advocated that HbA1c $\geq 7 \%$ is associated with higher rates of AVF failure or lower patency rate, ${ }^{[12,13]}$ whereas a recent prospective study has shown that HbA1c level is not related to delayed maturity. ${ }^{[14]}$ Afsar and Elsurer ${ }^{[12]}$ explain their findings mainly based on the assumptions that greater $\mathrm{HbA1c}$ levels indicate presence of DM and that greater HbA1c levels suggest poor glycemic control. The authors also suggested that peripheral artery disease, which they found to be associated with the increased HbA1c levels, might affect AVF failure. Singh et al. ${ }^{[14]}$ observed that those with $\mathrm{HbA} 1 \mathrm{c}$ $<6.5 \%$ had higher rates of AVF maturity at six weeks post-creation. Nevertheless, they demonstrated no significant relationship between $\mathrm{HbA1c}$ status and delayed maturity. Wu et al ${ }^{[13]}$ reported a direct effect of hyperglycemia on endothelium, yet underlined their apprehension on whether baseline glycemic status could reflect the severity of underlying diabetes.

Hyperglycemia is known to create tendency to thrombosis via blood flow retardation and platelet aggregation, ${ }^{[10]}$ which may eventually cause AVF failure. Although recent guidelines recommend the same target level of $\mathrm{HbA} 1 \mathrm{c}$ for patients with and without CKD, it is a matter of debate whether HbA1c level predicts blood glucose control accurately in CKD patients. It has been suggested by many authors that the correlation between $\mathrm{HbA} 1 \mathrm{c}$ and blood glucose is impaired in CKD patients and that $\mathrm{HbA} 1 \mathrm{c}$ may not be a reliable indicator of blood glucose control in these patients. ${ }^{[15,16]}$ Reduced red blood cell survival and common use of erythropoietin-stimulating agents increase the rate of young erythrocytes in these patients. These erythrocytes have less exposure time to glucose, which affects HbA1c levels. Several studies have indicated that the measured $\mathrm{HbA1c}$ levels of diabetic CKD patients are lower than indicated by their blood glucose levels, and thus HbA1c level mispresents glycemic control. ${ }^{[15,17]}$ Although it is beyond of our scope to assess the predictive value of $\mathrm{HbA} 1 \mathrm{c}$ level on blood glucose level in CKD patients, our analysis revealed no significant correlation between blood glucose levels and HbA1c levels in hemodialysis patients with DM. Although hyperglycemia seems to be an important parameter affecting AVF failure, it may be misleading to assess $\mathrm{HbA} 1 \mathrm{c}$ as an accurate predictor of blood glucose control in CKD patients. This may explain our finding that HbA1c level is not associated with AVF failure.

Vascular hyperglycemic memory is a relatively recent definition, describing the persistence of the effects of hyperglycemic stress, even though the blood glucose is normalized. ${ }^{[2]}$ This phenomenon makes the predictive value of the biochemical markers, which can only suggest recent blood glucose control, on vascular outcomes questionable, since recent blood glucose normalization does not rule out previous long-term hyperglycemia. Although the reliability of different markers remains being a matter of debate, it seems that any of these markers would be effective to predict AVF failure.

In our study, lower levels of platelet count were observed in patients with AVF failure. Although it is beyond doubt that thrombosis plays a role in the failure mechanism, an inverse association between platelet count and AVF failure is unexpected. Future studies should be made to analyze the effect of thrombosisrelated parameters on AVF failure.

The single-center, retrospective design with a relatively small sample size with AVF failure are the main limitations of our study. Another limitation is that no subgroup analysis was able to be made considering AVF locations. The AVFs with different arteries and veins may have different characteristics which can affect AVF maturation and, thus, AVF failure. However, our study includes only autogenous AVFs, created by a single surgeon, eliminating the effect of surgical approach on fistula failure. Besides, we reviewed an adequate number of primary AVF operations, suggesting that there is no predictive value of preoperative $\mathrm{HbA} 1 \mathrm{c}$ on primary AVF failure.

In conclusion, diabetes is associated with AVF failure irrespective of the patients' HbA1c levels. Although hyperglycemia seems to play a role in pathogenesis, there is a growing concern that $\mathrm{HbA} 1 \mathrm{c}$ level may not be accurately indicating blood glucose control in CKD patients. In addition, considering that biochemical markers fail to present previous long-term hyperglycemia, predictive value of these markers on 
vascular outcomes is limited. Based on these findings, the role of preoperative $\mathrm{HbA} 1 \mathrm{c}$ is limited in predicting primary AVF failure.

\section{Acknowledgements}

We would like to thank Prof. Dr. Hasan Güçlü, from the Department of Biostatistics, Faculty of Medicine, Istanbul Medeniyet University for his valuable assistance in statistical analysis.

\section{Declaration of conflicting interests}

The authors declared no conflicts of interest with respect to the authorship and/or publication of this article.

\section{Funding}

The authors received no financial support for the research and/or authorship of this article.

\section{REFERENCES}

1. National Kidney Foundation. KDOQI Clinical Practice Guideline for Diabetes and CKD: 2012 Update. Am J Kidney Dis 2012;60:850-86.

2. Paneni F, Beckman JA, Creager MA, Cosentino F. Diabetes andvasculardisease: Pathophysiology, clinicalconsequences, and medical therapy: Part I. Eur Heart J 2013;34:2436-43.

3. Lok CE, Huber TS, Lee T, Shenoy S, Yevzlin AS, Abreo K, et al. KDOQI Clinical Practice Guideline for Vascular Access: 2019 Update. Am J Kidney Dis 2020;75(4 Suppl 2):S1S164.

4. Hu H, Patel S, Hanisch JJ, Santana JM, Hashimoto T, Bai $\mathrm{H}$, et al. Future research directions to improve fistula maturation and reduce access failure. Semin Vasc Surg. 2016;29:153-71.

5. Vassalotti JA, Jennings WC, Beathard GA, Neumann $\mathrm{M}$, Caponi S, Fox $\mathrm{CH}$, et al. Fistula first breakthrough initiative: Targeting catheter last in fistula first. Semin Dial 2012;25:303-10.

6. Konner K, Nonnast-Daniel B, Ritz E. The arteriovenous fistula. J Am Soc Nephrol 2003;14:1669-80.

7. Keser BN, Kirman UN, Kocaaslan C, Aydin E. Theassociation between vascular access type and depressive symptoms in geriatric hemodialysis population. Vascular 2020;28:390-5.

8. Rooijens PP, Tordoir JH, Stijnen T, Burgmans JP, Smet de AA, Yo TI. Radiocephalic wrist arteriovenous fistula for hemodialysis: Meta-analysis indicates a high primary failure rate. Eur J Vasc Endovasc Surg 2004;28:583-9.

9. Huijbregts HJ, Bots ML, Wittens CH, Schrama YC, Moll FL, Blankestijn PJ; CIMINO study group. Hemodialysis arteriovenous fistula patency revisited: Results of a prospective, multicenter initiative. Clin J Am Soc Nephrol 2008;3:714-9.

10. Yan Y, Ye D, Yang L, Ye W, Zhan D, Zhang L, et al. A metaanalysis of the association between diabetic patients and AVF failure in dialysis. Ren Fail 2018;40:379-83.

11. Aronson D, Bloomgarden Z, Rayfield EJ. Potential mechanisms promoting restenosis in diabetic patients. J Am Coll Cardiol 1996;27:528-35.

12. Afsar B, Elsurer R. The primary arteriovenous fistula failure-a comparison between diabetic and non-diabetic patients: glycemic control matters. Int Urol Nephrol 2012;44:575-81.

13. Wu CC, Wen SC, Yang CW, Pu SY, Tsai KC, Chen JW. Baseline plasma glycemic profiles but not inflammatory biomarkers predict symptomatic restenosis after angioplasty of arteriovenous fistulas in patients with hemodialysis. Atherosclerosis 2010;209:598-600.

14. Singh P, Ariffin Z, Tajri H, Md Idris A, Suryati L, Sofida L. ROGAVF STUDY 2019 - Relationship of HbA1C (GLYCEMIC Control) on outcomes of AV FISTULAS: A prospective observational study. Arch Surg Clin Res 2019;3:53-55.

15. Vos FE, Schollum JB, Coulter CV, Manning PJ, Duffull SB, Walker RJ. Assessment of markers of glycaemic control in diabetic patients with chronic kidney disease using continuous glucose monitoring. Nephrology (Carlton) 2012;17:182-8.

16. Agarwal R, Light RP. Relationship between glycosylated hemoglobin and blood glucose during progression of chronic kidney disease. Am J Nephrol 2011;34:32-41.

17. Chujo K, Shima K, Tada H, Oohashi T, Minakuchi J, Kawashima S. Indicators for blood glucose control in diabetics with end-stage chronic renal disease: GHb vs. glycated albumin (GA). J Med Invest 2006;53:223-8. 